\title{
Development and application of 14 microsatellite markers in the burying beetle Nicrophorus vespilloides reveals population genetic differentiation at local spatial scales
}

\author{
Sonia Pascoal ${ }^{\text {Corresp., }}{ }^{1}$, Rebecca M Kilner ${ }^{1}$ \\ 1 Department of Zoology, University of Cambridge, Cambridge, United Kingdom \\ Corresponding Author: Sonia Pascoal \\ Email address: scm77@cam.ac.uk
}

Burying beetles (genus Nicrophorus) are relatively rare among insects in providing sophisticated parental care. Consequently, they have become model species in research analysing social evolution, the evolution of parental care and mating systems. We used the recently published $N$. vespilloides genome and transcriptome to develop microsatellite markers. Specifically, we developed 14 polymorphic markers with 5 to 13 alleles per locus and used them to investigate levels of genetic differentiation in four south Cambridgeshire (UK) populations of $N$. vespilloides, separated by $21 \mathrm{~km}$ at most. The markers revealed significant genetic structuring among populations ( $g$ lobal $F_{S T}=0.023$ ) with all but one of the pairwise comparisons among populations being significant. The single exception was the comparison between the two closest populations, which are approximately $2.5 \mathrm{~km}$ apart. In general, the microsatellite markers showed lower observed heterozygosity than expected. We infer that there is limited dispersal between populations and potentially also some inbreeding within them and suggest that this may be due to habitat fragmentation. We discuss these results in the context of recent laboratory experiments on inbreeding and beetle flight. 
1 Development and application of 14 microsatellite markers in the burying

2 beetle Nicrophorus vespilloides reveals population genetic differentiation at

local spatial scales

4

\author{
Sonia Pascoal* and Rebecca M. Kilner \\ Department of Zoology, University of Cambridge, Cambridge, CB2 3EJ, U.K. \\ *Corresponding author: $\underline{s c m 77 @, c a m . a c . u k}$
}

\title{
5 SUMMARY
}

6 Burying beetles (genus Nicrophorus) are relatively rare among insects in providing sophisticated

7 parental care. Consequently, they have become model species in research analysing social

8 evolution, the evolution of parental care and mating systems. We used the recently published $N$.

9 vespilloides genome and transcriptome to develop microsatellite markers. Specifically, we developed 14 polymorphic markers with 5 to 13 alleles per locus and used them to investigate levels of genetic differentiation in four south Cambridgeshire (UK) populations of $N$. vespilloides, separated by $21 \mathrm{~km}$ at most. The markers revealed significant genetic structuring among populations (global $\mathrm{F}_{\mathrm{ST}}=0.023$ ) with all but one of the pairwise comparisons among populations being significant. The single exception was the comparison between the two closest populations, which are approximately $2.5 \mathrm{~km}$ apart. In general, the microsatellite markers showed lower observed heterozygosity than expected. We infer that there is limited dispersal between populations and potentially also some inbreeding within them and suggest that this may be due to habitat fragmentation. We discuss these results in the context of recent laboratory experiments on inbreeding and beetle flight. 


\section{INTRODUCTION}

23

24

Burying beetles (genus Nicrophorus) are relatively unusual among insects in providing elaborate parental care for their developing larvae. Reproduction centres on the fresh carcass of a small vertebrate (like a songbird or mouse), which adults locate by flight. If more than one adult of the same sex finds the carcass, they will commonly fight to determine ownership (e.g. Otronen, 1988; Scott, 1994). Defeated subordinates may stay nearby: males may sneak matings with the dominant female, while females might become intraspecific brood parasites (e.g. Müller, Eggert \& Dressel, 1990; Hopwood et al., 2015). The dominant individuals of each sex then pair up and together prepare the carcass for reproduction (although mated females can singlehandedly raise young: Müller et al., 2007). They remove the fur or feathers, roll the flesh into a ball and bury it below ground in a shallow grave. During this time, parents defend their carcass breeding resource from attack by conspecifics, congenerics and other carrion-feeding insects (Robertson, 1993; Trumbo, 1990). Eggs are laid in the soil near the carcass. Newly hatched larvae crawl into a crater on the brood ball and there they solicit attention from their parents, who also stay to protect them from attack (Trumbo, 2007). About a week after the larvae hatch, the carcass is entirely consumed. The beetle parents then fly off to search for new mating opportunities or fresh carrion and the larvae disperse into the soil to pupate (Scott, 1998).

Burying beetles thus play a key ecological role as nutrient recyclers (e.g. Royle, Hopwood \& Head, 2013). Furthermore, their relatively unusual natural history, and the ease with which they can be bred in the lab, means that several have become popular study species in experimental analyses of social evolution, the evolution of parental care and mating systems (e.g. 
43 Royle, Hopwood \& Head, 2013; Scott, 1998). Nevertheless, despite their widespread use in the

44 lab, relatively little work has focused on the burying beetles' ecology in nature. This is because it

45 is difficult to track marked burying beetles through their life course to understand patterns of

46 dispersal (e.g. Attisano \& Kilner, 2015), the likely extent of competition for limited carrion

47 resources (e.g. Kilner et al., 2015), the degree of connectivity between populations and therefore

48 the potential for inbreeding (e.g. Pilakouta et al., 2015). Yet this knowledge is key for

49 interpreting the results of experiments carried out in the laboratory (e.g. Kilner et al., 2015,

50 Attisano \& Kilner, 2015, Pilakouta et al., 2015).

51 Furthermore, habitat fragmentation has recently been suggested to influence population

52 structure in beetles (Keller \& Largiader, 2003; Suzuki \& Yao, 2014). Habitat fragmentation by

53 deforestation has specifically been hypothesised to influence dispersal of $N$. americanus in the

54 USA (Creighton et al., 2009) and N. quadripunctatus populations in Japan (Suzuki \& Yao,

55 2014). Yet behavioural work on flight performance shows that burying beetles are capable of

56 sustained flight over tens of kilometres (Attisano \& Kilner 2015). Therefore a key aim of this

57 study was to determine the extent to which burying beetles disperse in nature over relatively

58 short distances, using genetic techniques (cf Houston et al., 2015).

Recently, molecular resources have been developed for $N$. vespilloides, including a genome, epigenome (Cunningham et al., 2015) and transcriptomes (e. g. Parker et al., 2015;

Palmer et al., 2016). We took advantage of these newly available molecular tools to develop microsatellite markers. We used the markers to determine the extent of genetic differentiation between natural populations of $N$. vespilloides, deliberately choosing sites on a local scale, no more than $21 \mathrm{~km}$ apart (Fig.1) to test the power of the markers we developed. These four populations were all in south Cambridgeshire and at: Waresley Woods (Latitude: 52.17487; 
66 Longitude: $-0.17354^{\circ}$ ), Gamlingay Woods (Latitude: 52.15555; Longitude: $-0.19286^{\circ}$ ), Byron’s

67 Pool (Latitude: 52.17305 ; Longitude: $0.10196^{\circ}$ ) and Madingley Woods (Latitude: 52.22658;

68 Longitude: $0.04303^{\circ}$ ). These four populations inhabit patches of woodland that are islands in a

69 landscape dominated by arable farmland and urban development. Their close proximity enabled

70 us to determine whether habitat fragmentation or beetle flight performance could better explain

71 population structure on a local scale.

72

MATERIAL AND METHODS

74

\section{Beetles}

Adult beetles from the four south Cambridgeshire populations (Fig.1): Gamlingay ( $\mathrm{n}=40$ ), Waresley $(n=40)$, Byron's Pool $(n=33)$ and Madingley $(n=26)$ were collected during MayOctober 2016 using Japanese beetle traps. Male and female beetles, sampled in equal numbers, were brought back to the laboratory alive and preserved in absolute ethanol for genetic analysis. In order to avoid collecting related individuals, periodical sampling was performed and only adult beetles (not larvae) were analysed. These were males and females attracted at random to the carcasses provided in the beetle traps.

In an earlier pilot study, we tested microsatellite markers from N. quadripunctatus, (Suzuki \& Yao, 2014) in N. vespilloides, but these failed to amplify reliably (Matthew Schrader, pers. comm.). We therefore developed new markers specifically for $N$. vespilloides.

DNA extraction, microsatellite amplification and analysis

Total genomic DNA ( $\mathrm{n}=139)$ was extracted individually from beetle heads using the DNeasy Tissue Kit (Qiagen). Molecular markers were developed with the program msatcommander 
89 (Faircloth, 2008), using the publicly available N. vespilloides genome (NCBI Bioproject number

90 PRJNA284849; Cunningham et al., 2015) and transcriptome (NCBI Bioproject PRJNA285436;

91 Parker et al., 2015). Twenty potential microsatellites were tested and optimised. From these, 14

92 polymorphic microsatellite markers were amplified using three primer mixes with the Qiagen

93 Multiplex PCR kit, following the manufacturer's instructions, to a final volume of $10 \mu \mathrm{L}$. The

94 fluorescent M13 tail single-reaction nested PCR method (Schuelke, 2000) using four tails

95 (Tysklind, 2009) was used to amplify the loci. An initial denaturation step of 15 minutes at $95^{\circ} \mathrm{C}$

96 was followed by 13 cycles at $94^{\circ} \mathrm{C}$ for $30 \mathrm{~s}, 62^{\circ} \mathrm{C}$ for $90 \mathrm{~s}$, and $72^{\circ} \mathrm{C}$ for $60 \mathrm{~s}$. In order to attach

97 the dye tails to the PCR product, an extra 31 cycles at $94^{\circ} \mathrm{C}$ of $30 \mathrm{~s}, 50^{\circ} \mathrm{C}$ for $90 \mathrm{~s}$ and $72^{\circ} \mathrm{C}$ for

$9860 \mathrm{~s}$ were performed and followed by a final extension at $60^{\circ} \mathrm{C}$ for 30 minutes. Extension

99 products were resolved on an ABI 3730 instrument at the Edinburgh Genomics Institute Sanger

100 Sequencing Centre with GeneScan 500 LIZ (Applied Biosystems) as internal size standard.

101 Alleles were scored and checked using Peak Scanner v.1.0 (Applied Biosystems).

102 GenAlEx version 6.5 (Peakall \& Smouse 2012) and FSTAT (Goudet, 1995) were used to

103 generate descriptive statistics (e.g. number of alleles, allelic frequencies, mean number of alleles

104 per locus and observed $\left(\mathrm{H}_{0}\right)$ and expected heterozygosity $\left.\left(\mathrm{H}_{\mathrm{E}}\right)\right)$. Tests for deviations from Hardy-

105 Weinberg proportions and genotypic linkage equilibrium were estimated using GENEPOP

106 (Raymond \& Rousset, 1995; Rousset, 2008). CERVUS v3.0.7 (Kalinowski et al., 2007) was used

107 to test for null alleles. Estimates of $\mathrm{F}_{\mathrm{ST}}, \mathrm{F}_{\mathrm{IS}}$, population pairwise $\mathrm{F}_{\mathrm{ST}}$ and their significance per

108 population over all loci were calculated using FSTAT (Goudet, 1995).

109

110 Results

111 Microsatellite development 
112 We screened the $N$. vespilloides genome (4660 contigs; NCBI Bioproject number

113 PRJNA284849) for microsatellite markers with at least 8 repeats for di- and trinucleotides and at

114 least 6 repeats for tetra-, penta- and hexanucleotides, and identified 1818 sequences containing

115 repeats. A total of 5547 microsatellites were present and 4515 primer pairs were obtained using

116 Primer3 (Rozen \& Skaletsky, 2000) incorporated into msatcommander (Faircloth, 2008). Similar

117 searches to the transcriptome identified 263 microsatellites and 69 primer pairs were designed.

118 To maximize the potential for amplification, we rejected primers of low quality, and that were

119 likely to self-anneal. To facilitate multiplexing, we chose markers from 100-500bp that varied in

120 size and the number of repeat motifs. To avoid linkage, we chose sequences with just one

121 marker. Twenty microsatellites were chosen for molecular marker optimization (16 from the

122 genome and 4 from the transcriptome). From these, a robust suite of 14 reliable microsatellites

123 was derived for the population genetic analysis (see Supplementary information). By 'robust' we

124 mean that they i) amplified reliably in all populations and in the majority of the samples; ii) did

125 not show secondary amplification; iii) were polymorphic in all populations; and iv) were

126 relatively easy to score (e.g. did not show stuttering).

Microsatellite analysis

All of the 139 N. vespilloides collected from the four Cambridgeshire populations were genotyped for the 14 microsatellites. All 14 loci were polymorphic for the tested populations and the number of alleles per locus ranged between 5 and 13, with a total number of 134 alleles

132 in the global sample (Table 1). The level of genetic variability was similar across loci. The expected heterozygosity $\left(\mathrm{H}_{\mathrm{E}}\right)$ per locus ranged from 0.272 to 0.841 , and the observed 
135 lower observed heterozygosity than expected heterozygosity (over all loci $\mathrm{H}_{\mathrm{E}}=0.714$ and

$136 \mathrm{H}_{\mathrm{O}}=0.652$ ). The expected heterozygosity across all loci per population ranged from 0.696 to

137 0.706, while the observed heterozygosity ranged from 0.638 to 0.679 (Table 2).

138 Tests for concordance with Hardy-Weinberg equilibrium (HWE) revealed deviations

139 from HWE in locus Nvesp_D, Nvesp_F, Nvesp_I, Nvesp_G and Nvesp_H (Table 1). Testing

140 HWE for individual populations and loci revealed that this disequilibrium remained significant

141 within populations (Nvesp_D: significant in all populations but Waresley; Nvesp_F: significant

142 for Byron's Pool only; Nvesp_I: significant in Waresley only; Nvesp_G: significant in Waresley

143 only; Nvesp_H: significant in Gamlingay and Byron's Pool) (Table 2). The frequency of null

144 alleles was low across loci (Table 1) and, overall, close to zero (indicating absence of null

145 alleles). However, three of the loci exhibiting deviations from HWE (Nvesp_D, Nvesp_I and

146 Nvesp_H) showed some of the highest null allele frequencies $(>0.05)$.

147 Evidence of linkage disequilibrium was observed in pairwise loci Nvesp_Q/Nvesp_E and 148 Nvesp_E/ Nvesp_G in the global population test. Global F IS value was 0.085 , suggesting some

149 heterozygous deficiency. A pattern of genetic differentiation (global $\mathrm{F}_{\mathrm{ST}}=0.023$ ) was observed in 150 the sampling area, with all but one significant population-pairwise $\mathrm{F}_{\mathrm{ST}}$ after Bonferroni

151 correction $(\alpha=0.008333)$. In order to assess whether there were potential biases in the markers

152 that exhibit deviations from HWE or the presence of potential null alleles, the analyses were run 153 with and without these markers. We found that the two runs rendered similar results (Fig. 1). 
156 We developed microsatellite markers to infer details of the burying beetle's ecology that cannot

157 be deduced through simple observation, but which are becoming increasingly important for the

158 interpretation of experiments on this species in the laboratory. The process of microsatellite

159 development was greatly facilitated by the existing N. vespilloides genome (Cunningham et al.,

160 2015) and transcriptome (Parker et al., 2015). The available genomic tools, however, are still

161 poorly annotated and so further detailed characterisation of the sequences containing the markers

162 is still limited (see Supplementary information). Nevertheless, our analyses suggest that the

163 markers are predominantly unlinked. We rapidly developed a set of 14 (out of 20) reliable

164 polymorphic markers for the species: i.e. 70\% were successful. This proportion of successful

165 markers is similar to that obtained for N. quadripunctatus (Suzuki \& Yao, 2014), although these

166 authors used enriched genomic libraries for marker development.

Our genetic analyses revealed significant deviations from Hardy-Weinberg equilibrium at

five loci. This is most likely due to an excess of homozygotes at these loci but could also be due

to the presence of null alleles in three of these markers. The only other marker with a putatively

high null allele frequency $(>0.05)$ was Nvesp_E. However, the high number of homozygotes for

171 this marker is unlikely to be due to null alleles because it is in HWE (Kalinowski et al., 2007).

172 We are confident that our results are not biased by including markers that deviated from HWE,

173 or potential null alleles, because we obtained similar results when we excluded these markers

174 from our analyses. In general, the microsatellite markers showed lower observed heterozygosity

175 than expected and the global $\mathrm{F}_{\mathrm{IS}}$ value (0.085) also suggested some heterozygosity deficiency.

176 We infer from these findings that there is limited gene flow between our study populations, and

177 potentially some inbreeding as well. The consequences of inbreeding in $N$. vespilloides have

178 recently been analysed experimentally in the laboratory (e.g. Mattey, Strutt \& Smiseth, 2013; 
179 Pilakouta et al., 2015; Pilakouta \& Smiseth, 2016) but to our knowledge, our study provides the

180 first indication that $N$. vespilloides might breed with relatives in nature and it matches previous

181 results obtained for N. quadripunctatus (Suzuki \& Yao, 2014).

182 Consistent with our interpretation of limited gene flow between populations, we found 183 significant pairwise population differentiation between all but one pair of populations (Waresley184 Gamlingay; approximately $2.5 \mathrm{~km}$ apart) despite the low geographical separation between the 185 sampling sites (maximum $20.3 \mathrm{~km}$ ). This genetic differentiation may be the result of neutral 186 population differentiation, or the effects of selection acting on functional genes correlated with 187 the neutral markers (e.g. Rousset \& Raymond, 1995). We think the former possibility is more likely because we obtained similar results when we ran the analyses with and without markers in HWE and because a BLASTx search showed that the markers did not generally correspond to (albeit limited) known coding genes in N. vespilloides.

Previous work on flight performance of $N$. vespilloides showed that these beetles have a wide distribution of flight distances in the laboratory ranging from $68 \mathrm{~m}$ to $26 \mathrm{~km}$. Furthermore, flight durations ranged from $61 \mathrm{~s}$ to $6.5 \mathrm{~h}$ under laboratory conditions (Attisano \& Kilner, 2015). Beetles tethered in flight mills may be able to fly for greater distances than naturally flying beetles because they bear less of their weight in flight. But even if we assume that beetles in natural flight cover only a third of the distance that they achieved in a flight mill, our data suggest that population differentiation within the sampling area is not solely attributable to the flight range of the burying beetle.

We suggest instead that habitat fragmentation has driven the fine-scale population structure we report here by imposing barriers that limit dispersal (cf Pascoal et al., 2009; Kanno 
202 beetles is increasingly reproductively isolated with increasing geographic distance between

203 woodlands. Perhaps $N$. vespilloides is unwilling, or unable, to undertake flights across open

204 fields and through housing. Studies of congeneric species (Nicrophorus marginatus, $N$.

205 tomentosus, $N$. orbicollis and $N$. defodiens) found that the size of these woodland fragments is

206 known to affect the abundance and reproductive success of the resident burying beetle

207 populations (Trumbo \& Bloch, 2000; Gibbs \& Stanton, 2001). Our analyses suggest that the

208 extent of their connectivity might also be an important factor for promoting gene flow and

209 preventing populations from becoming smaller and more inbred. If our interpretation is correct,

210 then it has important conservation implications because it suggests that there is a threshold size

211 of woodland required to sustain an outbreeding burying beetle population. It also might help

212 explain why populations of American burying beetles ( $N$. americanus) have collapsed so

213 spectacularly in recent years following substantial deforestation, causing it to become

214 endangered (Anderson, 1982; Creighton et al., 2009).

215 Although Single Nucleotide Polymorphism (SNPs) are starting to be the tool of choice

216 for population genetics/genomics studies, microsatellites still provide a cheaper alternative.

217 Nevertheless, we anticipate that the microsatellites we have developed will prove most useful in

218 future work for assigning parentage (Pascoal et al., in prep) because the large brood size

219 typically seen in $N$. vespilloides still makes other techniques prohibitively expensive. $N$.

220 vespilloides mates rampantly and promiscuously in the laboratory (e.g. House et al., 2009) and in

221 natural populations (e.g. Müller et al., 2007). Although several previous studies have analysed

222 strategies used by males for securing paternity (e.g. Eggert, 1992; House et al., 2009), parentage

223 has never before been assigned using microsatellites. The microsatellites we have developed here 
224 thus pave the way for more detailed analyses of the evolutionary causes and consequences of

225 promiscuity in this species.

226

227

REFERENCES

228

229

230

231

232

233

234

235

236

237

238

239

240

241

242

243

244

Anderson RS. 1982. On the decreasing abundance of Nicrophorus americanus Olivier (Coleoptera: Silphidae) in eastern North America. Coleopterists Bulletin 36:362-365.

Attisano A, Kilner RM. 2015. Parental care and flight behaviour in the burying beetle Nicrophorus vespilloides. Animal Behaviour 108:91-100.

Cotter SC, Littlefair, JE, Grantham PJ, Kilner RM. 2013. A direct physiological trade-off between personal and social immunity. Journal of Animal Ecology 82:846-853.

Creighton JC, Bastarache R, Lomolino MV, Belk MC. 2009. Effect of forest removal on the abundance of the endangered American burying beetle, Nicrophorus americanus (Coleoptera: Silphidae). Journal of insect conservation 13:37-43.

Cunningham CB, Lexiang J, Wiberg RAW, Shelton J, McKinney EC, Parker DJ, Meagher RB, Benowitz KM, Roy-Zokan EM, Ritchie MG, Brown SJ, Schmitz RJ, Moore AJ.

2015. The genome and methylome of a beetle with complex social behavior, Nicrophorus vespilloides (Coleoptera: Silphidae). Genome Biology and Evolution 7:3383-3396.

Eggert A-K. 1992. Alternative male mate-finding tactics in burying beetles. Behavioral Ecology 3:243-254.

Faircloth BC. 2008. Msatcommander: detection of microsatellite repeat arrays and automated, locus-specific primer design. Molecular Ecology Resources 8:92-94. 
245 Goudet J. 1995. FSTAT (version 1.2). A computer program to calculate F-statistics. Journal of 246 Heredity 86:385-386.

247

248

249

250

251

252

253

254

255

256

257

258

259

260

261

262

263

264

265

266

Gibbs JP, Stanton EJ. 2001. Habitat fragmentation and arthropod community change: carrion beetles, phoretic mites, and flies. Ecological Applications 11:79-85.

Hopwood PE, Moore AJ, Tregenza T, Royle NJ. 2015. Male burying beetles extend, not reduce, parental care duration when reproductive competition is high. Journal of Evolutionary Biology. 28: 1394-1402.

House CM, C. A. Walling CA, Stamper CE, Moore AJ. 2009. Females benefit from multiple mating but not multiple mates in the burying beetle Nicrophorus vespilloides. Journal of Evolutionary Biology 22:1961-1966.

\section{Houston DD, Mitchell KS, Clouse JW, Maughan PJ, Creighton JC, Smith AN, Bybee SM,} Belk MC. 2015. SNP development in North American burying beetles (Coleoptera: Silphidae): a tool to inform conservation decisions. Conservation Genetics Resources 349-52.

Kalinowski ST, Taper ML, Marshall TC. 2007. Revising how the computer program CERVUS accommodates genotyping error increases success in paternity assignment. Molecular Ecology 16:1099-1106.

Kanno Y, Vokoun JC, Letcher BH. 2011. Fine-scale population structure and riverscape genetics of brook trout (Salvelinus fontinalis) distributed continuously along headwater channel networks. Molecular Ecology 20:3711-3729.

Keller I, Largiader CR. 2003. Recent habitat fragmentation caused by major roads leads to reduction of gene flow and loss of genetic variability in ground beetles. Proceedings of the Royal Society of London B 270:417-423. 
267

268

Kilner RM, Boncoraglio G, Henshaw JM, Jarrett BJM, de Gasperin, Kokko H. 2015. Parental effects alter the adaptive value of an adult behavioural trait. eLife 4:e07340.

Mattey SN, Strutt L, Smiseth PT. 2013. Intergenerational effects of inbreeding in Nicrophorus vespilloides: Offspring suffer fitness costs when either they or their parents

are inbred. Journal of Evolutionary Biology 26:843-853.

Müller JK, Braunisch V, Hwang W, Eggert A-K. 2007. Alternative tactics and individual reproductive success in natural associations of the burying beetle, Nicrophorus vespilloides. Behavioral Ecology 18:196-203.

Müller JK, Eggert A-K, Dressel, J. 1990. Intraspecific brood parasitism in the burying beetle, Necrophorus vespilloides (Coleoptera: Silphidae). Animal Behaviour 40: 491-499.

Otronen M. 1988. The effect of body size on the outcome of fights in burying beetles (Nicrophorus) Annales Zoologici Fennici 25:191-201.

Palmer WJP, Duarte A, Schrader M, Day JP, Kilner RM, Jiggins F. 2016. A gene associated with social immunity in the burying beetle Nicrophorus vespilloides. Proceedings of the Royal Society of London B 283: 20152733.

\section{Parker DJ, Cunningham CB, Walling CA, Stamper CE, Head ML, Roy-Zokan EM,} McKinney EC, Ritchie MG, Moore AJ. 2015. Transcriptomes of parents identify parenting strategies and sexual conflict in a subsocial beetle. Nature Communications 6:8449.

Pascoal S, Creer C, Taylor MI, Queiroga H, Carvalho G, Mendo S. 2009. Development and application of microsatellites in Carcinus Maenas: genetic differentiation between northern and central Portuguese populations. PLoS ONE 4:e7268. 
288 Peakall R, Smouse PE. 2012. GenAlEx 6.5: genetic analysis in Excel. Population genetic

289 software for teaching and research — an update. Bioinformatics 28:2537-2539.

290

291

292

293

294

295

296

297

298

299

300

301

302

303

304

305

306

307

308

309

Pilakouta N, Smiseth PT. 2016. Maternal effects alter the severity of inbreeding depression in the offspring. Proceedings of the Royal Society of London B 283:20161023.

Pilakouta N, Halford C, Rácz R, Smiseth PT. 2016. Effects of prior contest experience and contest outcome on female reproductive decisions and offspring fitness. The American Naturalist 188:319-328.

Pilakouta N, Jamieson S, Moorad JA, Smiseth PT. 2015. Parental care buffers against inbreeding depression in burying beetles. Proceedings of the National Academy of Sciences $112: 8031-8035$

Raymond M, Rousset F. 1995. GENEPOP (version 1.2): population genetics software for exact tests and ecumenicism. Journal of Heredity 86:248-249.

Robertson IC. 1993. Nest intrusions, infanticide, and parental care in the burying beetle, Nicrophorus orbicollis (Coleoptera: Silphidae). Journal of Zoology London 231:583-593.

Rousset F. 2008. Genepop'007: a complete reimplementation of the Genepop software for Windows and Linux. Molecular Ecology Resources 8:103-106.

Rousset F, Raymond M. 1995. Testing heterozygote excess and deficiency. Genetics 140:14131419.

Royle NJ, Hopwood PE, Head ML. 2013. Burying beetles. Current Biology 20:R907-R909.

Rozen S, Skaletsky HJ. 2000. PRIMER 3 on the WWW for general users and for biologist programmers. In: Krawetz S, Misener S, editors. Bioinformatics Methods and Protocols: Methods in Molecular Biology. New Jersey: Humana press 365-386. 
310 Schwarz HH, Müller JK. 1992. The dispersal behavior of the phoretic mite Poecilochirus

311 carabi (Mesostigmata, Parasitidae): adaptation to the breeding biology of its carrier

312 Necrophorus vespilloides (Coleoptera, Silphidae). Oecologia 89:487-493.

313 Schuelke M. 2000. An economic method for the fluorescent labelling of PCR fragments. Nature 314 Biotechnology 18:233 - 234.

315 Scott MP. 1998. The ecology and behavior of burying beetles. Annual Review of Entomology $316 \quad 43: 595-618$.

Scott, MP. 1994. The benefit of paternal assistance in intra-and inter-specific competition for the burying beetle, Nicrophorus defodiens. Ethology Ecology and Evolution 6:537-543.

Suzuki S, Yao I. 2014. Isolation of nine polymorphic microsatellite loci from the burying beetle, Nicrophorus quadripunctatus (Coleoptera: Silphidae). Applied Entomology and Zoology 49:493-497.

Trumbo ST. 2007. Defending young biparentally: female risk-taking with and without a male in the burying beetle, Nicrophorus pustulatus. Behavioral Ecology and Sociobiology 61:17171723.

Trumbo ST, Bloch PL. 2000. Habitat fragmentation and burying beetle abundance and success. Journal of Insect Conservation 4:245-252.

Trumbo ST. 1990. Interference competition among burying beetles (Silphidae, Nicrophorus). Ecological Entomology 15:347-355.

Tysklind N. 2009. Population Genetic Markers in Biomonitoring Programmes: a Case Study of Flatfish around the British Isles. PhD Thesis, Bangor University, Bangor. 
331 Valtonen M, Palo JU, Aspi J, Ruokonen M, Kunnasranta M, Nyman T. 2014. Causes and

332 consequences of fine-scale population structure in a critically endangered freshwater seal. 333 BMC Ecology 14:e22.

334 Ward RJS, Cotter SC, Kilner RM. 2009. Current brood size and residual reproductive value 335 predict offspring desertion in the burying beetle Nicrophorus vespilloides. Behavioral 336 Ecology 20:1274-1281.

337

338

339

ACKNOWLEDGEMENTS

340

We thank Benjamin Jarrett, Syuan-Jyun Sun and Sue Aspinall for providing the field-caught

341 beetles for the genetic analysis.

342

343

344

345

346

347

348

349

350

351

352

\section{FIGURES}




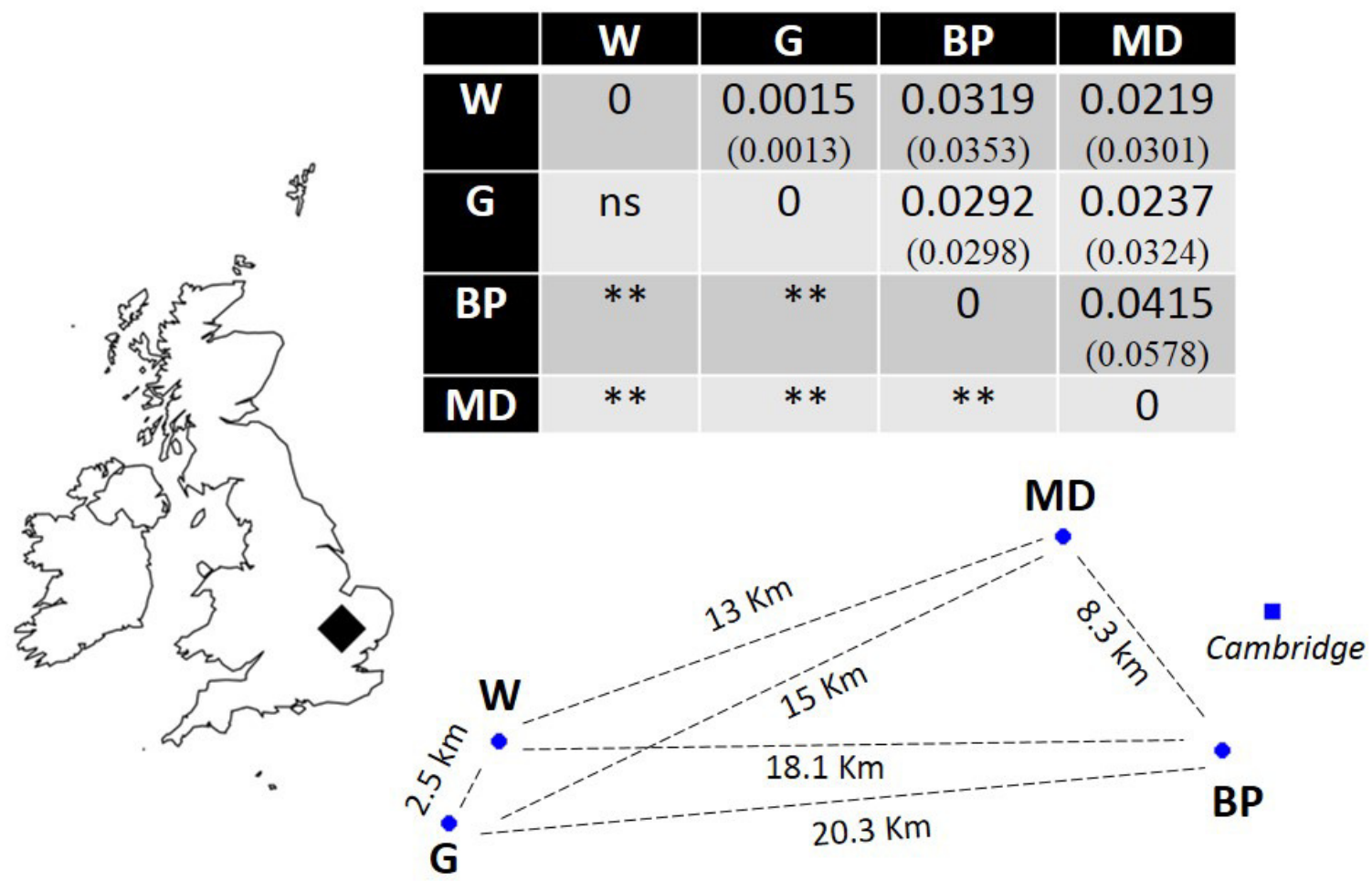

353

354

355

356

357

358

359

360

361

362

Figure 1. Sampling location in south Cambridgeshire and genetic differentiation in pairwise comparisons between populations. $P$ values for pairwise $\mathrm{F}_{S T}$ estimates across all loci are indicated below the diagonal, after Bonferroni correction $(\alpha=0.008333)$. Values in brackets represent the pairwise $\mathrm{F}_{\mathrm{ST}}$ values using only the 9 markers in HWE; the significance levels were identical in both runs. W: Waresley; G: Gamlingay; BP: Byron’s Pool; MD: Madingley.

Distances are "as the crow flies" distances calculated using online tools. The map and population's spatial representation (using the sites geographical coordinates) were produced in R. 
Table 1. Main genetic variability measures by locus of $N$. vespilloides from Cambridgeshire. $\mathrm{T}\left({ }^{\circ} \mathrm{C}\right)$ : annealing temperature; bp: base

367 locus; Null: frequency of null alleles per locus; HW: Hardy-Weinberg P values.

\begin{tabular}{|c|c|c|c|c|c|c|c|c|c|c|c|c|}
\hline Locus & Primer sequence $5^{\prime}-3^{\prime}$ & $\begin{array}{l}\text { Product } \\
\text { size (bp) }\end{array}$ & $\begin{array}{l}\text { Repeat } \\
\text { motif }\end{array}$ & $\mathbf{T}\left({ }^{\circ} \mathrm{C}\right)$ & PCR & Source & $\mathbf{N a}$ & $\mathbf{H}_{\mathbf{E}}$ & $\mathbf{H}_{\mathbf{O}}$ & $\mathbf{F}_{\text {ST }}$ & $\mathbf{F}_{\text {IS }}$ & Null \\
\hline Nvesp_A & F: Fam-CTACGGCGTGCAGAATTACC & 138 & $(\mathrm{AAC}) 9$ & 62 & Mix1 & G & 13 & 0.757 & 0.770 & 0.002 & -0.026 & $0 . \overline{114}$ \\
\hline Nvesp_D & $\begin{array}{l}\text { R: AACTCTCTGGTGTCGACGTC } \\
\text { F: Pet-TACGTGCGGTAATGAGGCG } \\
\text { R: ACGCCCTGCTCCCTATTTAG }\end{array}$ & 201 & $(\mathrm{AAC}) 11$ & 62 & Mix1 & $\mathrm{G}$ & 8 & 0.829 & 0.585 & 0.016 & 0.287 & 0.1701 \\
\hline Nvesp_J & $\begin{array}{l}\text { F: Vic-TGTGTGTAGAGTGGACGGG } \\
\text { R: TGGACGAGTTGAAGACGAGG }\end{array}$ & 303 & $(\mathrm{AAAG}) 7$ & 62 & Mix1 & G & 9 & 0.657 & 0.631 & 0.035 & 0.010 & 0.0131 \\
\hline Nvesp_M & $\begin{array}{l}\text { F: Ned-CCAGCAACCCACAAAGAAGC } \\
\text { R: ATACCACAAGTCCCGACCTG }\end{array}$ & 373 & $(\mathrm{AG}) 10$ & 62 & Mix1 & G & 11 & 0.841 & 0.825 & 0.019 & 0.039 & 0.0244 \\
\hline Nvesp_Q & $\begin{array}{l}\text { F: Fam-ATGCGGCTTTGATATCCAGG } \\
\text { R: TCAGATTCCGCTCTCCTTCC }\end{array}$ & 428 & $(\mathrm{AAT}) 8$ & 62 & Mix1 & G & 8 & 0.516 & 0.494 & 0.005 & 0.075 & 0.0560 \\
\hline Nvesp_B & $\begin{array}{l}\text { F: Fam-GTTGTTTCCGGTTGTTTGCG } \\
\text { R: TTCGAAGTTAAACGGCCGTG }\end{array}$ & 158 & $(\mathrm{AC}) 8$ & 62 & Mix2 & G & 10 & 0.723 & 0.701 & 0.021 & 0.035 & 0.0266 \\
\hline Nvesp_F & $\begin{array}{l}\text { F: Pet-TAAAGGGTTGGGAGGTTGGC } \\
\text { R: CACGATCCATACACGTGCAC }\end{array}$ & 216 & $(\mathrm{AC}) 10$ & 62 & Mix2 & G & 10 & 0.802 & 0.723 & 0.023 & 0.075 & 0.0458 \\
\hline Nvesp_I & $\begin{array}{l}\text { F: Vic-CTGATCACCGGAACCCTCTC } \\
\text { R: GAATTCCCGGGTTTATGCCG }\end{array}$ & 286 & $(A G) 8$ & 62 & Mix2 & $\mathrm{T}$ & 6 & 0.569 & 0.498 & 0.006 & 0.135 & 0.0793 \\
\hline Nvesp_P & $\begin{array}{l}\text { F: Fam-TGGTGATGCAATTGTGAGGC } \\
\text { R: CGGTTGGCAGACGATGTAAC }\end{array}$ & 410 & (ATC)8 & 62 & Mix2 & $\mathrm{G}$ & 9 & 0.809 & 0.741 & 0.028 & 0.082 & 0.0498 \\
\hline
\end{tabular}




\begin{tabular}{|c|c|c|c|c|c|c|c|c|c|c|c|c|}
\hline Nvesp_E & $\begin{array}{l}\text { F: Pet-ATGGATGGATGGAGAGTGGC } \\
\text { R: TTGATGGTTTCGAAAGGGCG }\end{array}$ & 201 & $(\mathrm{AC}) 8$ & 60 & Mix3 & $\mathrm{T}$ & 11 & 0.787 & 0.680 & 0.092 & 0.139 & 0.1109 \\
\hline Nvesp_G & $\begin{array}{l}\text { F: Fam-CGTGTGCGTGTTTCTACCTC } \\
\text { R: ATGGGCACGTATCCATACCC }\end{array}$ & 224 & $(\mathrm{AT}) 8$ & 60 & Mix3 & $\mathrm{T}$ & 12 & 0.834 & 0.776 & 0.013 & 0.064 & 0.0351 \\
\hline Nvesp_H & $\begin{array}{l}\text { F: Vic-TCGTAGATGTCTCGTGCCTG } \\
\text { R: CAGTTTGAAGGTGGTGGCTG }\end{array}$ & 283 & $(\mathrm{AG}) 9$ & 60 & Mix3 & G & 12 & 0.840 & 0.737 & 0.013 & 0.120 & 0.0669 \\
\hline Nvesp_K & $\begin{array}{l}\text { F: Ned-GCTCTCATTCTCCCAAACGC } \\
\text { GTGGACGCGCATAAGTTGTC }\end{array}$ & 334 & $(\mathrm{AGG}) 8$ & 60 & Mix3 & G & 5 & 0.272 & 0.247 & -0.002 & 0.085 & 0.0328 \\
\hline Nvesp_O & $\begin{array}{l}\text { F: Fam-ATGCCAATTAACGCGTCGAG } \\
\text { CATCGTTACCTGTGCGACTG }\end{array}$ & 395 & $(\mathrm{AAG}) 8$ & 60 & Mix3 & G & 10 & 0.760 & 0.718 & 0.013 & 0.054 & 0.0387 \\
\hline All & & & & & & & 134 & 0.714 & 0.652 & 0.023 & 0.085 & \\
\hline
\end{tabular}

Table 2. Main genetic variability measures for Cambridgeshire populations. W: Waresley; G: Gamlingay; BP: Byron's Pool; MD:

376 Madingley; $\mathrm{N}$ : mean number of samples per locus; $\mathrm{N}$-all: mean number of alleles per locus; $\mathrm{H}_{\mathrm{E}}$ : expected heterozygosity; $\mathrm{H}_{\mathrm{O}}$ :

377 observed heterozygosity; A-O refers to Nvesp_A-Nvesp_O. 


\section{Hardy-Weinberg $\boldsymbol{P}$ values}

\begin{tabular}{|c|c|c|c|c|c|c|c|c|c|c|c|c|c|c|c|c|c|c|}
\hline Pop & $\mathbf{N}( \pm \mathbf{S D})$ & N-all( \pm SD $)$ & $\mathbf{H}_{\mathbf{E}}( \pm \mathrm{SD})$ & $\mathbf{H}_{\mathbf{O}}( \pm \mathrm{SD})$ & $\mathbf{A}$ & D & $\mathbf{J}$ & $\mathbf{M}$ & $\mathbf{Q}$ & B & $\mathbf{F}$ & I & $\mathbf{P}$ & $\mathbf{E}$ & $\mathbf{G}$ & $\mathbf{H}$ & $\mathbf{K}$ & $\mathbf{O}$ \\
\hline \multirow{2}{*}{ W } & 38.143 & 7.571 & 0.699 & 0.679 & 0.25 & 0.14 & 0.63 & 0.22 & 0.52 & 0.18 & 1.00 & 0.00 & 0.83 & 0.32 & 0.00 & 0.29 & 1.00 & 0.54 \\
\hline & (0.619) & $(0.453)$ & $(0.047)$ & $(0.046)$ & 5 & 1 & 2 & 8 & 9 & 0 & 0 & 9 & 4 & 8 & 4 & 7 & 0 & 4 \\
\hline \multirow{2}{*}{ G } & 37.214 & 7.714 & 0.706 & 0.638 & 0.66 & 0.00 & 0.96 & 0.11 & 0.03 & 0.26 & 0.53 & 0.28 & 0.16 & 0.22 & 0.35 & 0.00 & 0.06 & 0.02 \\
\hline & $(0.639)$ & $(0.474)$ & $(0.043)$ & $(0.045)$ & 5 & 0 & 9 & 5 & 6 & 7 & 5 & 2 & 4 & 1 & 1 & $\mathbf{0}$ & 4 & 8 \\
\hline \multirow{2}{*}{ BP } & 29.714 & 7.429 & 0.702 & 0.664 & 0.42 & 0.01 & 0.90 & 0.02 & 0.19 & 0.85 & 0.00 & 0.20 & 0.25 & 0.08 & 0.13 & 0.01 & 0.43 & 0.90 \\
\hline & $(0.485)$ & $(0.581)$ & $(0.043)$ & $(0.049)$ & 8 & 6 & 8 & 2 & 1 & 5 & $\mathbf{0}$ & 6 & 6 & 3 & 6 & 7 & 6 & 4 \\
\hline \multirow[t]{2}{*}{ MD } & 19.286 & 6.429 & 0.696 & 0.649 & 0.28 & 0.03 & 0.05 & 0.93 & 0.59 & 0.60 & 0.10 & 0.51 & 0.10 & 0.57 & 0.18 & 0.10 & 0.23 & 0.07 \\
\hline & $(0.606)$ & $(0.343)$ & $(0.044)$ & $(0.045)$ & 8 & 7 & 9 & 6 & 8 & 7 & 2 & 8 & 3 & 1 & 3 & 0 & 2 & 1 \\
\hline
\end{tabular}

